\title{
Anatomía del rizoma y de la parte basal, media y distal del vástago de Solidago chilensis var. chilensis (Asteraceae)
}

\author{
Anatomy of the rhizome and the basal, middle and distal zone of \\ Solidago chilensis var chilensis (Asteraceae) shoot
}

D.0.I.: doi.org/10.30550/j.lil/2018.55.1/5

\author{
Perez, Beatriz*; Daiana M. Carrettoni; Bruno A. Lus; Nancy M. Apóstolo \\ Programa Interdisciplinario de Estudios en Plantas Vasculares. Departamento de Ciencias Básicas, \\ Universidad Nacional de Luján, CC 6700 Luján, Buenos Aires, Argentina. \\ * Autor corresponsal: perezbea99@gmail.com
}

\begin{abstract}
- Resumen - Solidago chilensis var. chilensis "vara de oro" es una hierba perenne rizomatosa, nativa de la Argentina. Se la utiliza en medicina popular como vulnerario, antilítico y diurético y presenta actividad farmacológica gastroprotectora, antibacterial, antiinflamatoria y antioxidante. El objetivo de este trabajo es caracterizar la anatomía de la zona basal, media y distal del vástago y el rizoma de Solidago chilensis var. chilensis en estado vegetativo con el fin de estudiar futuras relaciones entre partes de la planta y la producción de fitoquímicos y para contribuir a caracterizarla como droga cruda. El vástago, rizoma y raíces adventicias de individuos vegetativos recolectados en la provincia de Buenos Aires fueron divididos en tres zonas (distal, media y basal o proximal) y estudiados mediante técnicas histológicas convencionales para microscopía óptica y electrónica de barrido. Los resultados muestran que los tricomas eglandulares látigo y cónicos se localizan principalmente en las hojas. La densidad de los tricomas látigo es mayor en las hojas de las zonas distal superior y media. Los tricomas glandulares biseriados sólo están presentes en la zona distal del vástago y en los catafilos del rizoma. Los estomas se localizan en ambas epidermis foliares, pero su densidad es menor en las hojas basales. Hay espacios secretores esquizógenos en todos los órganos analizados. En las hojas están asociados al xilema y floema, y sólo al floema en los catafilos. En el tallo, rizoma y raíces están en la corteza asociados al floema, y se encuentran muy bien desarrollados en la zona distal del vástago. Tallos, rizomas y raíces presentan aerénquima en la corteza, el cual desarrolla espacios intercelulares más grandes en sus correspondientes partes basales o proximales. Los cristales de oxalato de calcio en forma de ráfides, estiloides y prismas son abundantes en el aerénquima y médula del tallo distal superior.
\end{abstract}

Palabras clave: Estructuras secretoras; hoja; rizoma; tallo; tricomas.

Abstract - Solidago chilensis var. chilensis "goldenrod" is a rhizomatous perennial herb native to Argentina. It is used in popular medicine as antilithic, diuretic and vulnerary; it also has pharmacological activity as a gastroprotective, antibacterial, anti-inflammatory and antioxidant. The objective of this study is to characterize the anatomy of the basal or proximal, middle and distal zones of the stem and the rhizome of Solidago chilensis var. chilensis in

Ref. bibliográfica: Pérez, B., Carrettoni, D. M., Lus, B. A., Apóstolo, N. M. (2018). Anatomía del rizoma y de la parte basal, media y distal del vástago de Solidago chilensis var. chilensis (Asteraceae). Lilloa 55 (1): 49-66.
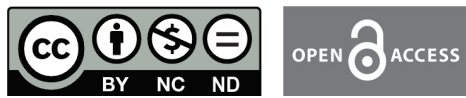

Recibido: 16/03/18 - Aceptado: 22/05/18

$>$ URL de la revista: http://lilloa.lillo.org.ar

Algunos derechos reservados. Esta obra está bajo una Licencia Creative Commons Atribución - No Comercial - Sin Obra Derivada 4.0 Internacional. 
vegetative state to study future relations between parts of the plant and the production of phytochemicals, and to contribute to its characterization as a crude drug. The stem, rhizome and adventitious roots of vegetative individuals collected in the province of Buenos Aires were divided into three zones (distal, middle and basal or proximal) and studied by conventional histological techniques for optical and scanning electron microscopy. The results show that non-glandular whip and conical trichomes are located mainly in the leaves. The density of whip trichomes is higher in the leaves of the distal and middle stem. Biseriate glandular trichomes are only present in the distal leaves and stem and in the scales of the rhizome. The stomata are located in both foliar epidermis, but its density is lower in the basal leaves. There are schizogenous secretory spaces in all analyzed organs. In the leaves are associated with xylem and phloem, and in the scales, only with phloem. In the stem, rhizome and roots, they are located in the cortex associated with phloem; they are very well developed in the distal leaves and stem. Stems, rhizomes and roots have aerenchyma in the cortex, which develops larger intercellular spaces towards their basal or proximal zones. Calcium oxalate crystals in the form of needles, styloids and prisms are abundant in the aerenchyma and pith of the stem upper distal zone.

Keywords: Leaf; rhizome; secretory structures; stem; trichomes.

\section{INTRODUCCIÓN}

El género Solidago L. (Asteraceae, Astereae) comprende aproximadamente 120 especies, distribuidas en su mayoría en América del Norte y unas pocas en América del Sur, Europa y Asia (López Laphitz y Semple, 2015). De las cuatro especies que crecen en Argentina, Solidago chilensis Meyen var. chilensis, actualmente la única variedad de la especie, es la de más amplia distribución. Se la encuentra en casi todo el territorio argentino, Brasil, Bolivia, Paraguay, Uruguay y Chile, desde el nivel del mar hasta los 2600 m snm (Sancho, Viera Barretto, Vitali, 2014; López Laphitz y Semple, 2015).

Solidago chilensis var. chilensis es una hierba perenne, conocida comúnmente como «vara de oro», «vara dorada», «romerillo amarillo»y «penacho». Posee tallos erguidos simples de 0,60-2,50 m de altura (Ahumada et al., 2016) (Fig. 1A). Las hojas son simples, alternas, sésiles, lineares a angostamente oblanceoladas o elípticas, de 20-90 x 0,3-15 mm, gradualmente menores hacia el ápice; base atenuada; ápice agudo; margen aserrado en la porción distal; tres nervios bien marcados (Sancho et al., 2014) (Fig. $1 B, C)$. Produce una vistosa inflorescencia terminal piramidal con flores amarillas. Se reproduce vegetativamente por rizomas (Fig. 1D, E). Crece en suelos húmedos, campos abandonados y bordes de caminos, y es una maleza de varios cultivos, pasturas y montes frutales (Marzocca, 1997; Ahumada et al., 2016).

En la Argentina, las hojas de $S$. chilensis se emplean por vía oral como diurético y sedativo y en fomentos como vulnerario (Lahitte et al., 1998). Las raíces son empleadas como anticefalálgico y antilítico y las inflorescencias, como sedativo (Lahitte et. al., 1998; Alonso y Desmarchelier, 2015). En Brasil, el macerado de la planta se usa para traumatismos, dolores musculares y picaduras de insectos (Alonso y Desmarchelier, 2015). Además, los rizomas frescos se utilizan como diurético, antihelmíntico y estimulante del apetito (Mercandeli, Bessa, Ronchi, Segato, da Silva, 2012). La especie presenta actividad farmacológica gastroprotectora, antibacteriana, antimicótica, antiinflamatoria, antioxidante, antirreumática y para tratar externamente el lumbago (Güntner et al., 1999; Silva et al., 2010; Vila et al., 2002; Barboza, Cantero, Núñez, Pacciaroni, Ariza Espinar, 2009; Tamura et al., 2009; Bucciarelli, Minetti, Milczakowskyg, Skliar, 2010; Mercandeli et al., 2012; Alonso y Desmarchelier, 2015).

Debido a su importancia medicinal, valor ornamental y también por su toxicidad para el ganado, se han realizado algunos trabajos anatómicos en Solidago chilensis. Varios autores describieron el tallo, raíz, hoja, rizoma y algunas de las estructuras reproductivas (Hernández, Martínez Alonso, Morandi, Arambarri, 2013; Hernández et al., 2015; 

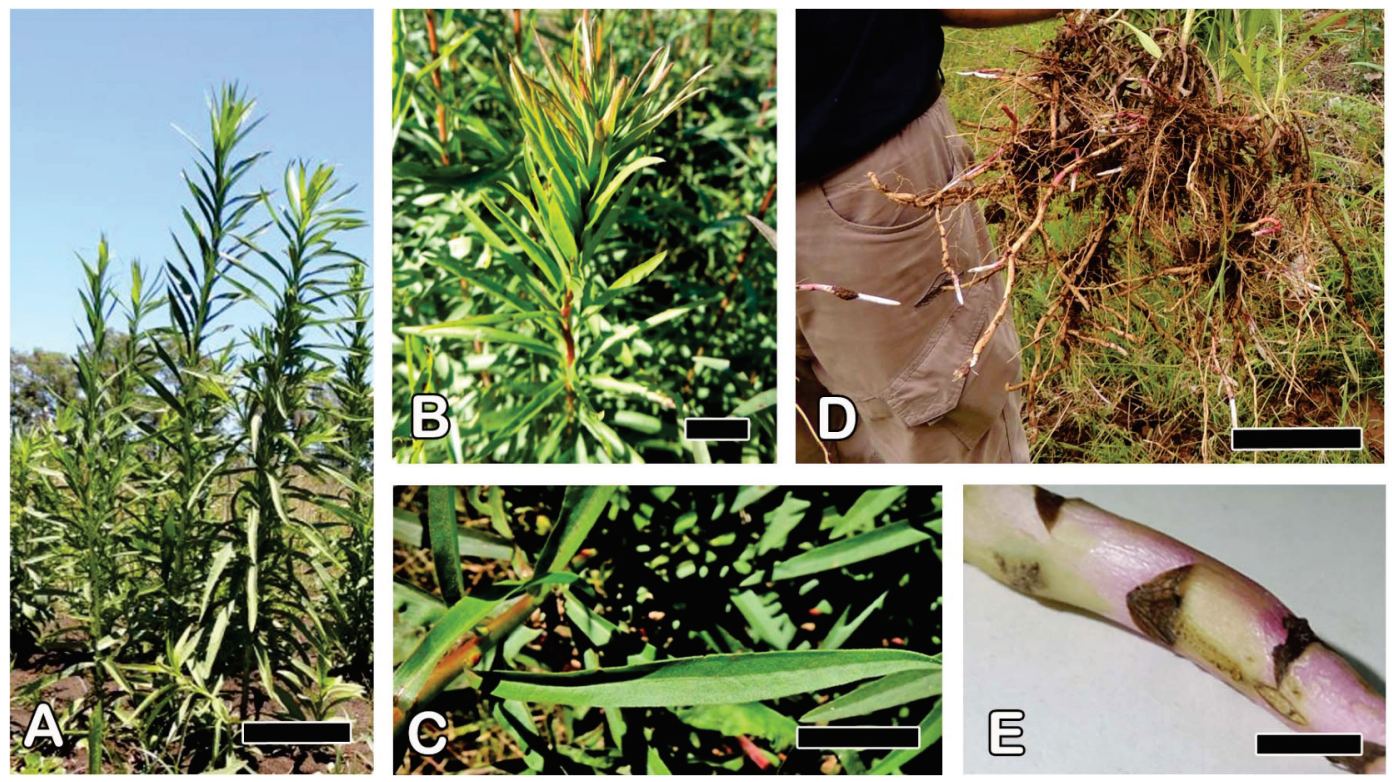

Fig. 1. Solidago chilensis var. chilensis. Morfología. A) Aspecto general de la planta en estado vegetativo. B] Hojas de la zona distal del vástago (apicales y superiores]. C) Hoja de la zona media del vástago. D) Órganos subterráneos: rizomas y raíces. E) Detalle de rizoma y catafilos. Barras: A: $30 \mathrm{~cm}$; B, C: $2 \mathrm{~cm}$; D: $10 \mathrm{~cm}$; $: 1 \mathrm{~cm}$.

Colares et al., 2014; Souza, Sá, Araújo, Randau, 2017) a fin de caracterizar la especie en droga cruda. La epidermis foliar fue descripta brevemente por Freire et al. (2005) con el objeto de identificar especies de Angiospermas perjudiciales para el ganado en la depresión del Salado en la provincia de Buenos Aires. Gil, Seisdedos, Reyna y Cerana (2012) también estudiaron la epidermis foliar como carácter diagnóstico adaptativo, con el fin de considerar el uso en jardinería en ambientes áridos de la provincia de Córdoba.

Los estudios sobre la estructura interna de Solidago chilensis se limitan a caracterizar un solo sector de tallos, rizomas y raíces de individuos adultos, e incluso algunos de ellos no indican de qué parte de la planta ha sido colectada cada muestra. Además, estos trabajos aportan información escasa o incompleta sobre la morfología y distribución de estructuras secretoras especializadas, las cuales podrían estar relacionadas con la producción de fitoquímicos de interés medicinal.

El estudio de la anatomía de una especie medicinal permite su identificación en mezclas o herbarios comercializados como droga cruda, lo cual garantiza su identidad botánica (Barboza et al., 2001) y asegura su calidad, seguridad y eficacia farmacológica. La caracterización de sólo una parte de la planta podría no ser suficiente para su reconocimiento y podría llevar a errores al momento de detectar falsificaciones o adulteraciones. Asimismo, existe información de que se producen diferentes tipos de metabolitos en los distintos estados de desarrollo de los órganos de un ejemplar (Arambarri y Hernández, 2014; Rodríguez Morcelle et al., 2015). Por lo tanto, el conocimiento anatómico de los órganos vegetativos en diversos niveles de desarrollo podría ser útil en la determinación del momento de cosecha adecuado para la obtención de compuestos de interés medicinal.

En el marco de un proyecto de estudios integrales de especies medicinales nativas de la provincia de Buenos Aires con el fin de lograr su domesticación, el objetivo de este trabajo es estudiar la anatomía de la zona distal, basal y media del vástago y el rizoma de Solidago chilensis var. chilensis en estado vegetativo. 


\section{MATERIALES Y MÉTODOS}

Se colectaron muestras de vástago y rizoma de seis ejemplares de Solidago chilensis var. chilensis en estado vegetativo, con una altura de 1,50-1,60 m, localizadas en poblaciones naturales del partido de Luján y alrededores (Buenos Aires, Argentina). El material de referencia es: Solidago chilensis Meyen var. chilensis, ARGENTINA, Prov. Buenos Aires, Pdo. Luján, alrededores de la Universidad Nacional de Luján, 34³4'40" S, 5905'22" O, 21 m snm, 25-IV-2014, Costaguta 216 (LP).

El vástago de dichas plantas fue dividido en tres zonas: distal, media y basal. La zona distal fue subdividida en dos niveles, el apical, compuesto por los nudos 15 al 20 desde el ápice, con hojas sin expandir totalmente, y el superior, desde el nudo 20 al 30 desde el ápice (Fig. 1B). La zona basal abarcaba desde el cuello de la planta hasta el nudo 20 desde la base. La zona media, la más extensa, era la comprendida entre la zona distal y la basal (Fig. 1C). Independientemente de su posición en el tallo, los cortes transversales de hoja se realizaron en la parte media de la lámina.

Por otra parte, fueron tomadas muestras de los rizomas más extensos: en la zona distal (cinco nudos desde el ápice), proximal (cinco nudos desde el nacimiento del rizoma), y media (entre las zonas anteriores). También se obtuvieron muestras de las raíces adventicias.

El material fue fijado en FAA (ácido acético: formaldehído: etanol 960: agua destilada, 1:2:10:7), incluido en parafina y cortado con micrótomo rotatorio Microm HM 325 en forma transversal, paradermal y longitudinal, según el órgano. Los preparados fueron coloreados con safranina y verde rápido y montados en resina sintética Entellan, según metodología convencional (D’Ambrogio de Argüeso, 1986; Zarlavsky, 2014). También se hicieron preparados temporarios de cortes transversales realizados a mano libre a partir de material fresco para completar observaciones de contenidos celulares. Se realizó la prueba histoquímica con Lugol $\left(\mathrm{I}_{2}-\mathrm{KI}\right)$ para identificación de almidón. La presencia de cristales se determinó con microscopio UNICO equipado con filtro polarizador y cámara digital Moticam.

Por otro lado, fueron efectuadas técnicas de impronta y peeling (D'Ambrogio de Argüeso, 1986; Zarlavsky, 2014) para el estudio de la superficie de ambas epidermis de las hojas frescas de las diferentes partes del vástago. Los peelings fueron clarificados con hipoclorito de sodio, coloreados con safranina diluida y montados en agua-glicerina. Las improntas fueron obtenidas con esmalte sintético de uñas y montadas en agua-glicerina.

Las observaciones y micrografías de los cortes, peelings e improntas fueron realizadas con microscopio óptico Nikon Eclipse E200 (Japón), equipado con cámara digital Moticam.

Por otra parte, tallos y hojas del vástago fueron acondicionados para observar sus superficies con microscopio electrónico de barrido Philips modelo XL30 TMP New Look (Eindhoven, Netherlands). Para ello, las muestras fueron deshidratadas con una serie de alcoholes de graduación ascendente, luego secadas con punto crítico y, posteriormente, metalizadas con oro-paladio (D’Ambrogio de Argüeso, 1986).

La clasificación de estomas se realizó según Metcalfe y Chalk (1979) y la de tricomas, según Uphof (1962).

Sobre ocho preparaciones de hojas de cada zona del vástago analizada (distal superior, media y basal), se determinó la densidad de estomas y de tricomas de la epidermis abaxial y adaxial. Por cada epidermis en cada tipo de hoja, se determinaron las densidades (estomas $/ \mathrm{mm}^{2}$ y tricomas $/ \mathrm{mm}^{2}$ ) en, al menos, tres áreas al azar. Los resultados fueron analizados mediante ANOVA y test de Tukey ( $\mathrm{p} \leq 0,05)$ con SPSS 15.0.

\section{RESULTADOS}

\section{ANATOMÍA DE LA HOJA}

Todas las hojas del vástago presentan similar anatomía, pero tienen algunos caracteres diferenciales según su posición en el tallo. 
Tabla 1. Características foliares cuantitativas: densidad de estomas, tricomas eglandulares látigo o flageliformes y tricomas glandulares biseriados en hojas de tres zonas del tallo de Solidago chilensis var. chilensis (media \pm desvío estándar, expresado en número por $\mathrm{mm}^{2}$ ). *Letras minúsculas diferentes indican diferencias significativas entre zonas del tallo. ** Letras mayúsculas diferentes indican diferencias significativas entre las caras de la hoja de una misma zona. (ANOVA y test de Tukey, $p \leq 0,05$ ).

\begin{tabular}{|c|c|c|c|c|c|c|c|c|c|}
\hline \multirow[b]{2}{*}{ Zona en el tallo } & \multicolumn{2}{|c|}{ Densidad de estomas } & \multicolumn{3}{|c|}{ Densidad de tricomas látigo } & \multicolumn{4}{|c|}{ Densidad de tricomas glandulares } \\
\hline & Adaxial & Abaxial & Adaxial & Abaxial & & Adaxia & & Abaxial & \\
\hline Hoja distal superior & $152,41 \pm 16,78 a^{*} B^{* *}$ & $199,20 \pm 13,08 a \quad A$ & $17,23 \pm 3,81 \mathrm{a} \quad A$ & $16,45 \pm 4,10 \mathrm{a}$ & A & $18,58 \pm 0,82$ & A & $18,04 \pm 0,75$ & A \\
\hline Hoja media & $169,75 \pm 16,78$ а в & $224,25 \pm 14,31 \mathrm{a} \quad \mathrm{A}$ & $18,66 \pm 6,66$ a $A$ & $18,63 \pm 6,69 a$ & A & 0 & & 0 & \\
\hline Hoja basal & $92,88 \pm 15,26 b \quad B$ & $126,37 \pm 18,63 b \quad A$ & $4,00 \pm 2,47$ b $\quad A$ & $4,95 \pm 3,23 b$ & A & 0 & & 0 & \\
\hline
\end{tabular}

En vista superficial, las células epidérmicas propiamente dichas de ambas caras de la hoja son pequeñas, poligonales, de contorno recto o levemente sinuoso (Fig. 2A, B). Este tipo de células, en conjunto con los estomas, forman pequeñas áreas que están rodeadas por células epidérmicas propiamente dichas alargadas y paralelas entre sí asociadas al trayecto de las nervaduras (Fig. 2A, C). Todas las células epidérmicas presentan cutícula estriada (Fig. 2A). Los estomas de ambas epidermis están rodeados por 3-5 células vecinas, siendo en su mayoría anomocíticos y algunos anisocíticos (Fig. 2B). Independientemente del tipo estomático, los estomas son más numerosos en la cara abaxial de las hojas de todas las zonas del tallo (Tabla 1). La mayor densidad estomática se encuentra en las hojas de las zonas distal superior y media (Tabla 1). 2C):

Se observaron tres tipos de tricomas (Fig.

Tipo I: Eglandular látigo o flageliforme (Fig. 2D, E). Uniseriado, compuesto por cuatro células. La célula basal está dispuesta sobre el nivel de las restantes células epidérmicas y tiene forma de pequeño cono truncado. El cuerpo tiene dos células, la inferior con forma cilíndrica o de cuña y la superior con forma cilíndrica o de barril. La célula terminal del tricoma es angosta y alargada, recta u ondulante, del mismo largo o más que el resto del tricoma. Este tipo de tricomas se distribuyen sobre las nervaduras y el margen de la hoja. Su densidad es similar en ambas epidermis de la lámina, pero se encuentran en mayor cantidad en las hojas de las zonas distal superior y media (Tabla 1).
Tipo II: Eglandular cónico (Fig. 2F-G). Uniseriado. Posee una base de células de disposición radiada, un cuerpo de 3-7 células de paredes gruesas y una célula terminal aguzada. Es el tipo de tricoma de mayor dimensión entre los observados. Se localizan mayoritariamente en el margen foliar de las hojas de todos los sectores del tallo, donde tienen disposición antrorsa. Sin embargo, se observan escasos de estos tricomas en la lámina y nervaduras de la hoja.

Tipo III: Glandular biseriado (Fig. $2 \mathrm{H}$, I). Constituido por 4-6 pares de células de disposición subopuesta. La secreción se acumula en un espacio subcuticular entre las dos células apicales. Se localizan en las hojas de las zonas distal apical (Fig. 2I; 3G) y superior del tallo en ambas epidermis, principalmente sobre las venas y el margen de las hojas. La densidad de este tipo de tricomas es similar en ambas epidermis de la hoja distal superior (Tabla 1).

El transcorte de las hojas de las zonas distal, media y basal del tallo muestra una epidermis uniestratificada con cutícula gruesa (Fig. 3A, C, E). Las células epidérmicas pueden contener antocianinas. Los estomas se encuentran a nivel de la epidermis y sus cámaras subestomáticas son amplias (Fig. 3A, C). El mesofilo tiene una estructura isolateral, con 3-4 capas de parénquima en empalizada hacia ambas epidermis. Entre ambos clorénquima en empalizada, se observan 1-(2) capas de parénquima incoloro de células grandes con muy pocos cloroplastos (Fig. 3A, C, E) La nervadura media de las hojas es muy prominente en la cara abaxial y casi plana o levemente convexa hacia la adaxial; otras nervaduras 

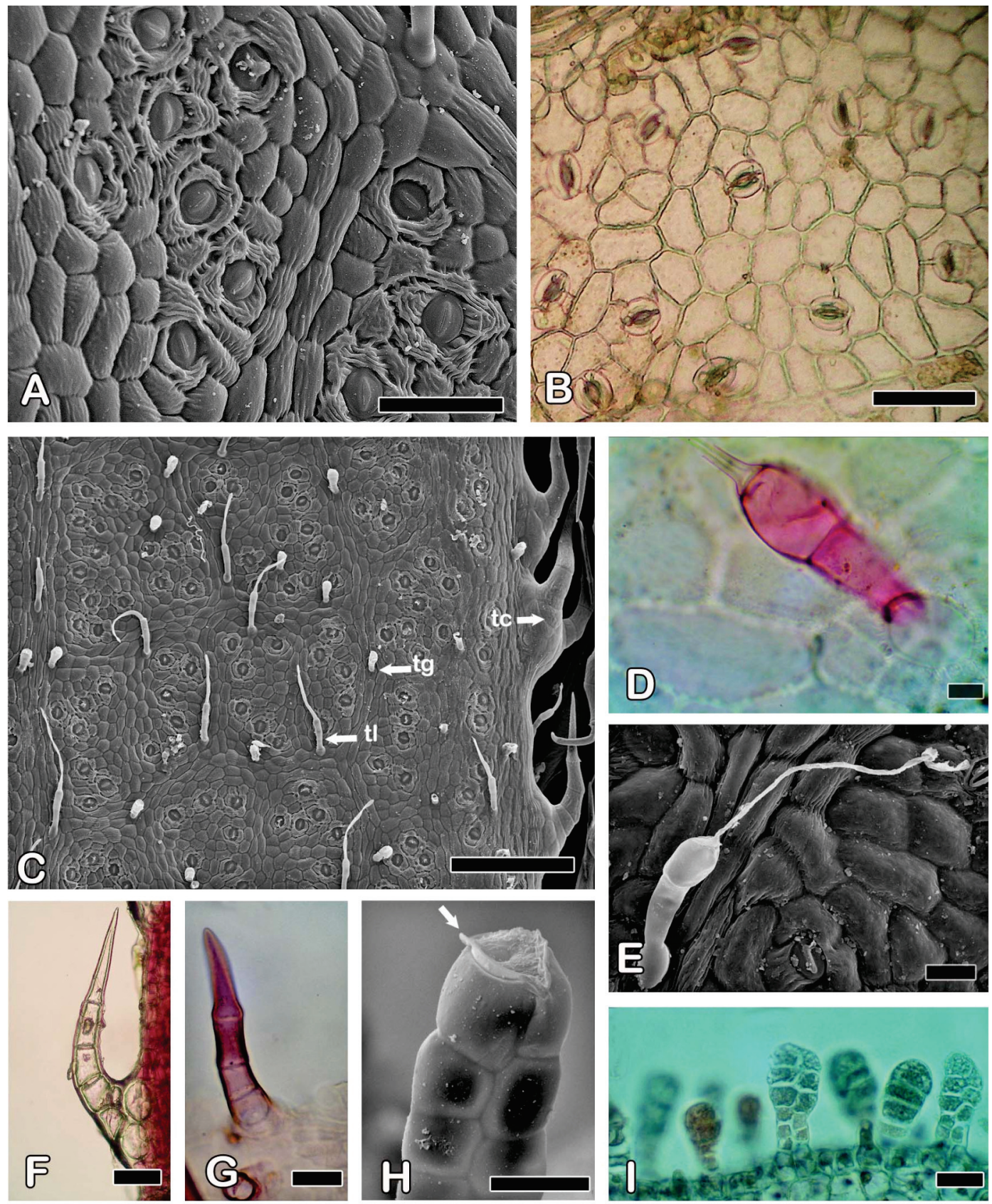

Fig. 2. Solidago chilensis var. chilensis. Superficie foliar. A) Cara adaxial de la hoja distal superior. B) Cara abaxial de la hoja distal superior. C) Indumento en la cara adaxial de la hoja distal superior. D, E) Tricomas eglandulares látigo o flageliformes. F) Tricoma eglandular cónico en margen de la hoja distal superior. G) Tricoma cónico en superficie adaxial de la hoja distal superior. H) Tricoma glandular biseriado en hoja distal superior (flecha señala la línea de ruptura de la cutícula). I) Tricomas glandulares biseriados en hoja distal apical. Referencias: tc, tricoma eglandular cónico; tg, tricoma glandular; tl, tricoma eglandular látigo o flageliforme. A, C, E, H: Microscopio electrónico de barrido; B, D, F, G, I: Microscopio óptico. Barras: A, B, F: $50 \mu \mathrm{m}$; C: $200 \mu \mathrm{m}$; D-E, G, I: $20 \mu \mathrm{mm} ; \mathrm{H}: 10 \mu \mathrm{m}$. 

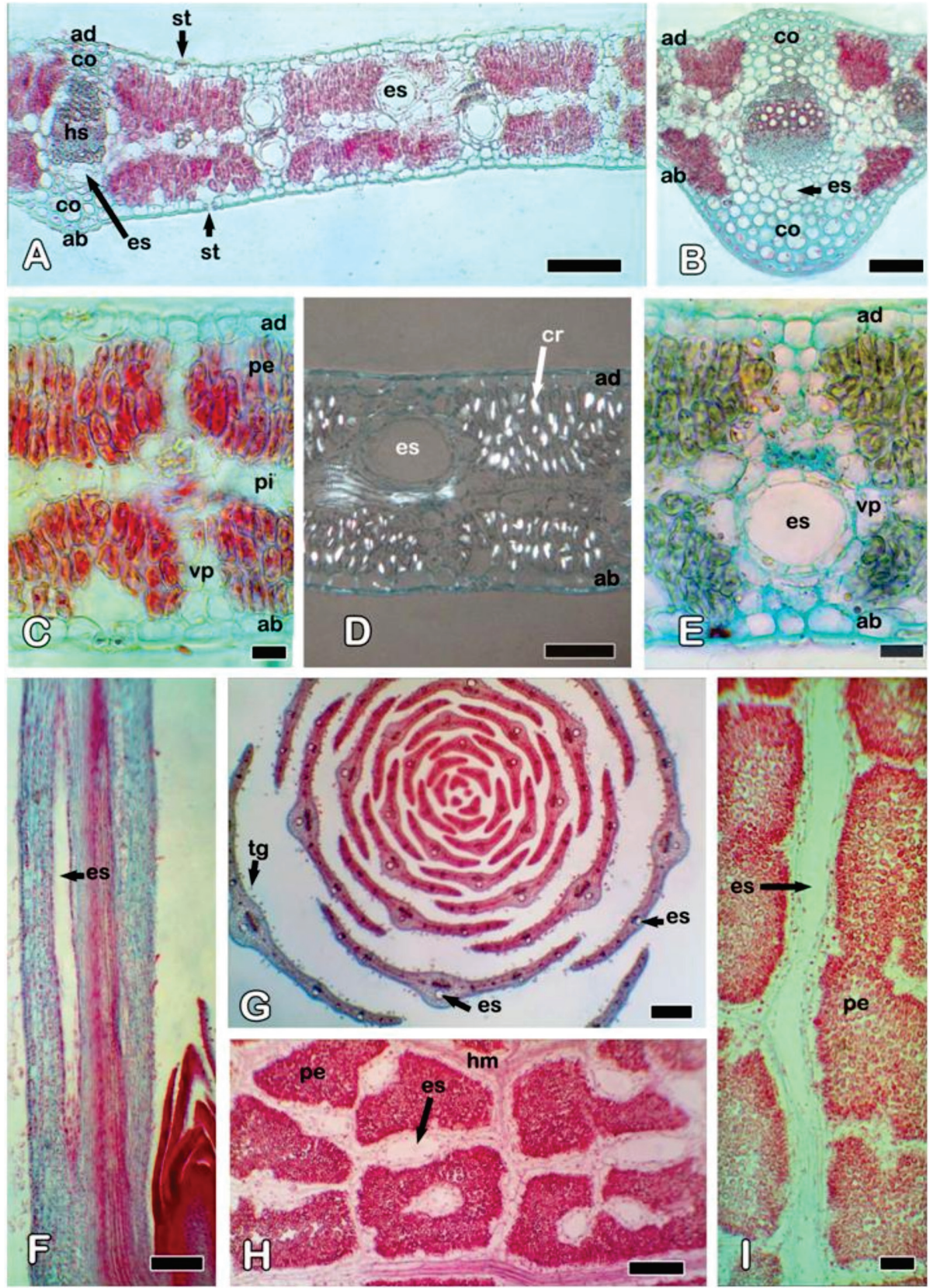

Fig. 3. Solidago chilensis var. chilensis. Estructura interna de la hoja, microscopio óptico. A] Aspecto general de la hoja de la zona media del vástago, CT. B) Vena media de hoja de la zona media del vástago, CT. C) Mesofilo de la hoja de la zona media, CT. D) Distribución de cristales de oxalato de calcio en el mesofilo de hoja distal superior, CT, luz polarizada. E) Vena menor y espacio secretor de la hoja distal superior, CT. FJ Espacio secretor en hoja distal apical, corte longitudinal. G) Hojas de la zona distal apical, CT. H, I) Espacio secretor en corte paradermal de la hoja distal superior. Referencias: ab, epidermis abaxial; ad, epidermis adaxial; co, colénquima; cr: cristales; CT, corte transversal; es, espacio secretor esquizógeno; hm: haz menor; hs: haz secundario; st, estoma; pe, parénquima en empalizada; pi, parénquima incoloro; tg, tricoma glandular; vp, vaina parenquimática. Barras: A, B, H: $100 \mu \mathrm{m}$; C, E: 20 $\mu \mathrm{m} ; \mathrm{D}, \mathrm{I}: 50 \mu \mathrm{m} ; \mathrm{F}, \mathrm{G}: 200 \mu \mathrm{m}$. 
importantes pueden ser levemente convexas hacia una o ambas caras (Fig. 3A, B). Los haces vasculares son colaterales, rodeados por una vaina parénquimática de células incoloras grandes con extensiones hacia ambas caras, sólo hacia una de ellas o sin extensiones (Fig. 3A, C, E). En la vena principal hay un haz vascular rodeado por una vaina parenquimática poco notable, colénquima hacia ambas caras de la hoja y parénquima incoloro. A nivel de las venas de mayor orden también se puede encontrar colénquima, y en algunos haces, incluido el de la vena media, se pueden hallar casquetes de fibras floemáticas $\mathrm{y} / \mathrm{o}$ xilemáticas (Fig. 3A, B).

Se observan espacios o reservorios secretores de origen esquizógeno incluidos en la vaina de los haces vasculares y asociados tanto con el floema, el xilema o con ambos (Fig. 3A, B, E). Sin embargo, algunos haces no tienen reservorios (Fig. 3C) y se exhiben muy pocos reservorios que no están asociados a haces. Las estructuras secretoras están delimitadas por una capa epitelial de un número variable de células cuadrangulares o rectangulares. Poseen un lumen circular de diámetro variable, los menos amplios se encuentran en la nervadura media y otras venas importantes y los más amplios están asociados a venas menores (Fig. 3A, B, E, G). En el corte longitudinal y paradermal de la hoja (Fig. 3F, H, I), los espacios se ven más o menos alargados, elípticos o circulares. Las hojas sin expandir del nivel apical tienen espacios secretores conspicuos (Fig. 3G).

Se encontraron cristales de oxalato de calcio en forma de ráfides, estiloides, prismas alargados, cúbicos y bipiramidales. Son muy abundantes en las células del parénquima en empalizada (Fig. 3D). Por otro lado, no están presentes en las hojas del nivel distal apical.

\section{ANATOMÍA DEL TALLO AÉREO}

El tallo presenta un contorno general circular en las zonas distal, media y basal.

En vista superficial, las zonas distal apical y distal superior muestran una cutícula con estrías alargadas, mientras que en las zonas media y basal presenta ceras epicuticulares en forma de escamas (Fig. 4A-C). $\mathrm{El}$ aspecto general del tallo es glabrescente, pero se encuentran los mismos tipos de tricomas descriptos en las hojas. Los tricomas tipo I y II son escasos y están ausentes en las zonas media y basal del tallo (Fig. 4A, B). Los tricomas tipo III sólo están en las zonas distal apical y distal superior, donde se los encuentra en importante cantidad (Fig. 4D). Los estomas, en general, son escasos en el tallo (Fig. 4C).

Entre la zona distal y la basal del tallo se observa un cambio gradual en la conformación de los tejidos (Fig. 4D-G). El corte transversal de las zonas distal apical y distal superior del tallo presenta crecimiento primario (Fig. 4D, E). La zona distal superior muestra la epidermis uniestratificada con células cuadrangulares o rectangulares y cutícula gruesa. La corteza tiene 1-3 capas de colénquima continuo, típicamente laminar. El resto de la corteza muestra varias capas de aerénquima (Fig. 4E), entre las que pueden encontrarse esclereidas circulares dispersas. El colénquima y aerénquima contienen cloroplastos y las células epidérmicas y colenquimáticas pueden contener antocianinas (Fig. 5A). La zona cortical en contacto con la estela está conformada por una endodermis con bandas de Caspary y pequeños amiloplastos (Fig. 5B). Los numerosos haces vasculares colaterales se disponen en eustela y presentan casquetes de fibras floemáticas. Gran parte del centro del tallo está ocupado por una médula de células parenquimáticas circulares grandes de paredes delgadas y pequeños espacios intercelulares (Fig. 4E). Algunas de las células de la médula se pueden transformar en esclereidas. Se observan espacios esquizógenos corticales, similares a los descriptos en las hojas, en proximidad de la endodermis y a nivel del floema, en número de uno por haz vascular (Fig. 4E). En corte longitudinal del tallo, estos espacios se muestran alargados (Fig. 4J). Ráfides, estiloides y prismas de oxalato de calcio son abundantes en el aerénquima y en la médula del tallo distal superior y son escasos en la epidermis y el colénquima (Fig. 5C-E). 

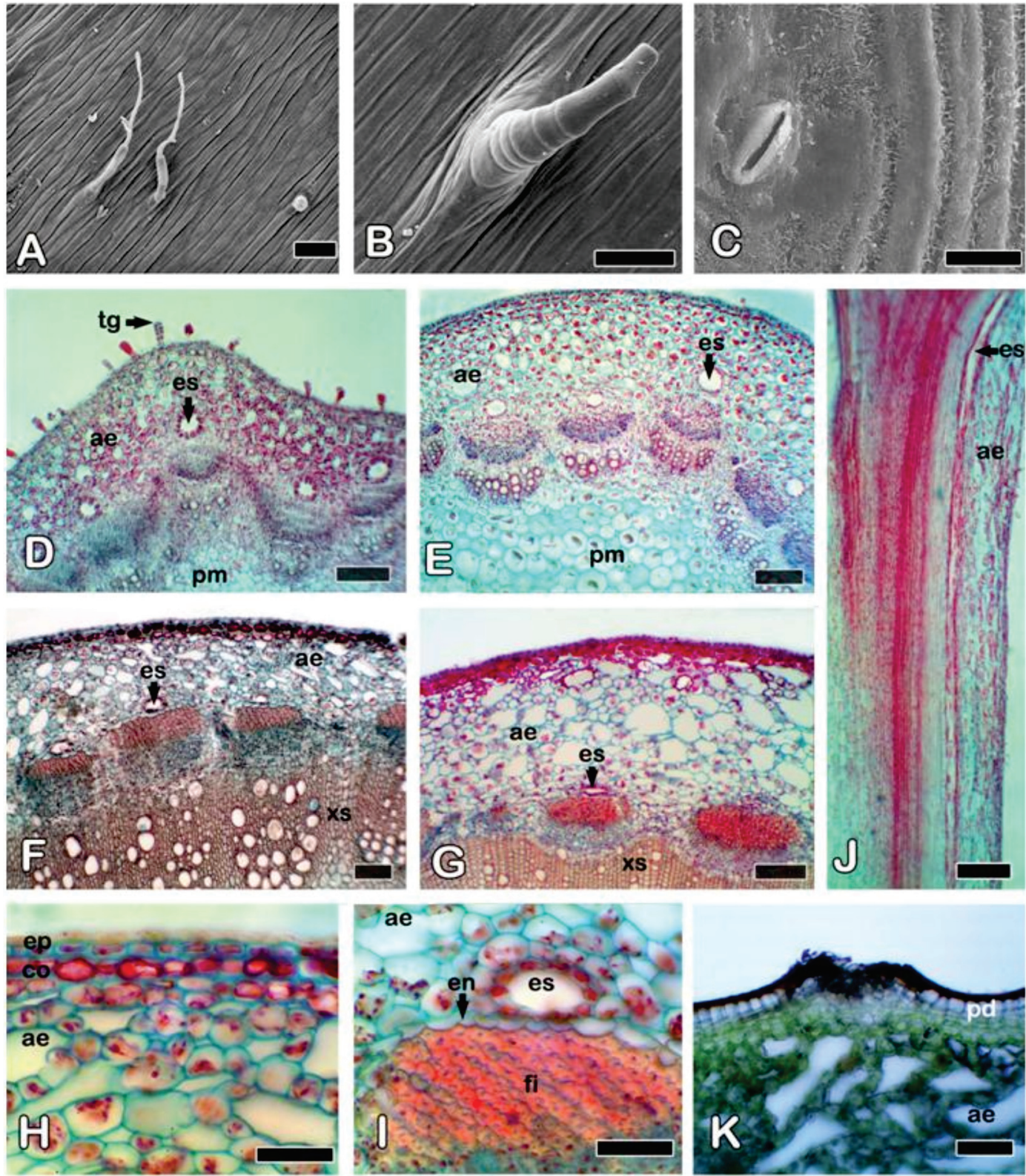

Fig. 4. Solidago chilensis var. chilensis. Estructura interna y micromorfología del tallo aéreo. A) Tricomas eglandulares látigo de la zona distal superior, vista superficial. B] Tricoma eglandular cónico de la zona distal superior, vista superficial. C) Estoma y cutícula de la zona basal, vista superficial. D) Aspecto general de la zona distal apical, CT. E) Aspecto general de la zona distal superior, CT. F) Aspecto general de la zona media, CT. G] Aspecto general de la zona basal, CT. H) Detalle de epidermis y corteza de la zona media, CT. I) Detalle del espacio secretor y endodermis de la zona media, CT. J) Espacio secretor en la zona distal superior, corte longitudinal. K) Detalle de la peridermis en la zona basal, CT. Referencias: ae, aerénquima; co, colénquima; CT, corte transversal; en: endodermis; es, espacio secretor esquizógeno; ep: epidermis; fi, fibras; pd: peridermis; pm: parénquima medular; tg: tricoma glandular; xs, xilema secundario. A-C: Microscopio electrónico de barrido; D-K: Microscopio óptico. Barras: A, B, H, I: $50 \mu \mathrm{m}$; C: $20 \mu \mathrm{m}$; J: $200 \mu \mathrm{m}$; D-G, K: $100 \mu \mathrm{m}$. 

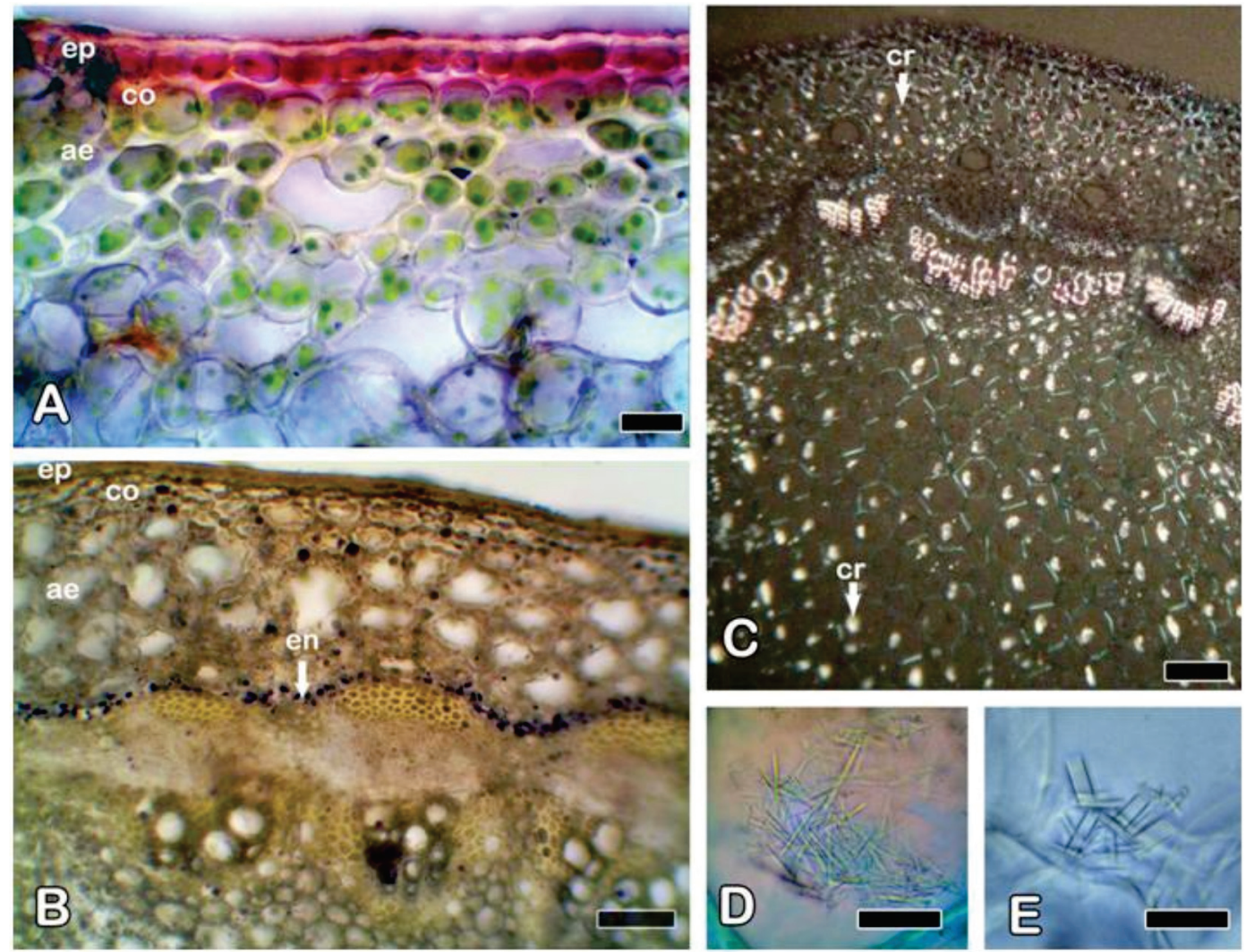

Fig. 5. Solidago chilensis var. chilensis. Contenidos celulares en transcorte de tallo aéreo, microscopio óptico. A] Antocianinas y cloroplastos en la zona distal superior. B] Amiloplastos en endodermis (tinción Lugol) en la zona distal superior. C) Distribución de los cristales de oxalato de calcio en la zona distal superior, luz polarizada. DJ Ráfides. E) Estiloides. Referencias: ae: aerénquima; co: colénquima; $c r$ : cristales; en: endodermis; ep: epidermis. Barras: A, D, E: $20 \mu \mathrm{m} ; \mathrm{B}, \mathrm{C}: 100 \mu \mathrm{m}$.

En la zona distal apical del tallo, el colénquima puede no estar desarrollado aún, y el parénquima de la corteza va aumentando el tamaño de sus espacios intercelulares hasta transformarse en aerénquima. Los espacios secretores esquizógenos son muy conspicuos en esta zona del tallo (Fig. 4D). No se observaron cristales en esta parte del tallo.

En la zonas media y basal se encuentran los mismos tejidos que muestra la zona distal superior del tallo (Fig. 4F-I), pero con desarrollo de tejido vascular secundario, radios pluriseriados y abundantes fibras xilemáticas y floemáticas (Fig. 4F, G). Los espacios intercelulares del aerénquima son más numerosos y de mayor tamaño que en la zona distal del tallo (Fig. 4F, G) y puede haber abundantes esclereidas entre las células parenquimáticas corticales. Muchos de los canales esquizógenos se presentan colapsados (Fig. 4F, G). La zona basal del tallo exhibe una incipiente peridermis (Fig. 4K). Tanto en la zona media como en basal son escasos los cristales de oxalato de calcio.

\section{ANATOMÍA DEL RIZOMA, CATAFILOS Y RAÍCES ADVENTICIAS}

Los rizomas jóvenes son delgados, blanquecinos o con coloraciones rosadas (Fig. 1D, E). En vista superficial de la zona distal, algunas de las células epidérmicas son de forma poligonal y pueden contener antocianinas; los estomas son escasos (Fig. 6A). 
En el transcorte de la zona distal se observa crecimiento primario (Fig. 6B). La epidermis es uniestratificada con cutícula gruesa. Subepidérmicamente se observa una capa de felógeno formada por células rectangulares altas (Fig. 6C). El resto de la corteza está conformada por varias capas de aerénquima (Fig. 6B), entre cuyas células se pueden encontrar esclereidas como las descriptas en el tallo aéreo (Fig. 6D, E). La capa cortical interna es una endodermis con bandas de Caspary, sin amiloplastos. El cilindro vascular está representado por una eustela de numerosos haces vasculares colaterales con casquetes de fibras floemáticas (Fig. 6B). $\mathrm{Al}$ igual que en el tallo aéreo, se observan espacios esquizógenos corticales asociados al floema, los cuales se ven alargados en el corte longitudinal del rizoma (Fig. 6B, F). La médula está formada por células parenquimáticas grandes y pequeños espacios intercelulares.

En las zonas media y proximal del rizoma (Fig. 6G-I) hay desarrollo de tejidos vasculares secundarios y puede encontrarse una incipiente peridermis. Los espacios intercelulares del aerénquima son más grandes hacia la zona proximal, pero no tan importantes como los observados en el tallo aéreo. La abundancia de las esclereidas en el parénquima cortical aumenta hacia la zona proximal del rizoma. No se observó correspondencia entre diámetro del rizoma y desarrollo de los tejidos vasculares secundarios, ya que se encontraron rizomas de gran grosor con escaso desarrollo de xilema secundario y otros con menor grosor y mayor crecimiento secundario.

En todos los sectores del rizoma se observaron algunos cristales de oxalato de calcio en forma de prismas, ráfides y estiloides, en el aerénquima y en la médula. También se encontraron escasos esferocristales de inulina.

Los catafilos de los rizomas jóvenes son de forma triangular y base ancha y se disponen alternadamente (Fig. 1E). En vista superficial, las células epidérmicas típicas de estas hojas son poligonales, algunas con paredes sinuosas, y pueden contener anto- cianinas. Los estomas son escasos y están presentes en ambas superficies de la hoja modificada (Fig. 7A). En los márgenes de los catafilos se localizan tricomas similares a los ya descriptos, pero los de tipo II son pequeños y de la misma longitud que los tricomas tipo I (Fig. 7B). En transcorte, los catafilos presentan ambas epidermis uniestratificadas con células cuadrangulares y cutícula estriada, más gruesa en la cara abaxial (Figs. 6B; 7C, D). Hacia la epidermis abaxial se observa una hipodermis uniestratificada con células grandes incoloras (Fig. 7C, D). El resto del mesofilo está formado por parénquima incoloro. Hay una nervadura media más prominente con un haz vascular y espacios secretores esquizógenos grandes asociados al floema de los haces vasculares (Fig. 7E). No se observaron cristales en la estructura interna del catafilo.

Las raíces adventicias son delgadas y nacen en los nudos y entrenudos de los rizomas, aunque también en la base de los tallos aéreos, con origen endógeno (Figs. 1D; 6F). En transcorte, estas raíces presentan una actinostela 3-6 arca (Fig. 8A, B). En las zonas media y proximal de la raíz, la actinostela presenta desarrollo secundario con abundantes fibras xilemáticas y floemáticas (Fig. 8B). La corteza está representada por células parenquimáticas, más grandes hacia el centro de la raíz, y en las raíces de mayor diámetro se observa un incipiente aerénquima por la presencia de espacios intercelulares más notables (Fig. 8C, D). La capa cortical más externa es una exodermis y la más interna es una endodermis con bandas de Caspary. En la zona cortical en contacto con la endodermis y a la altura del floema, se observan espacios secretores esquizógenos (Fig. 8A-D). Estos espacios secretores no están desarrollados o son muy pequeños en la zona más distal cercana al ápice de la raíz. En las raíces de mayor diámetro puede desarrollarse una peridermis incipiente. Se encontraron escasos cristales de oxalato de calcio y esferocristales de inulina en la corteza de la raíz. 

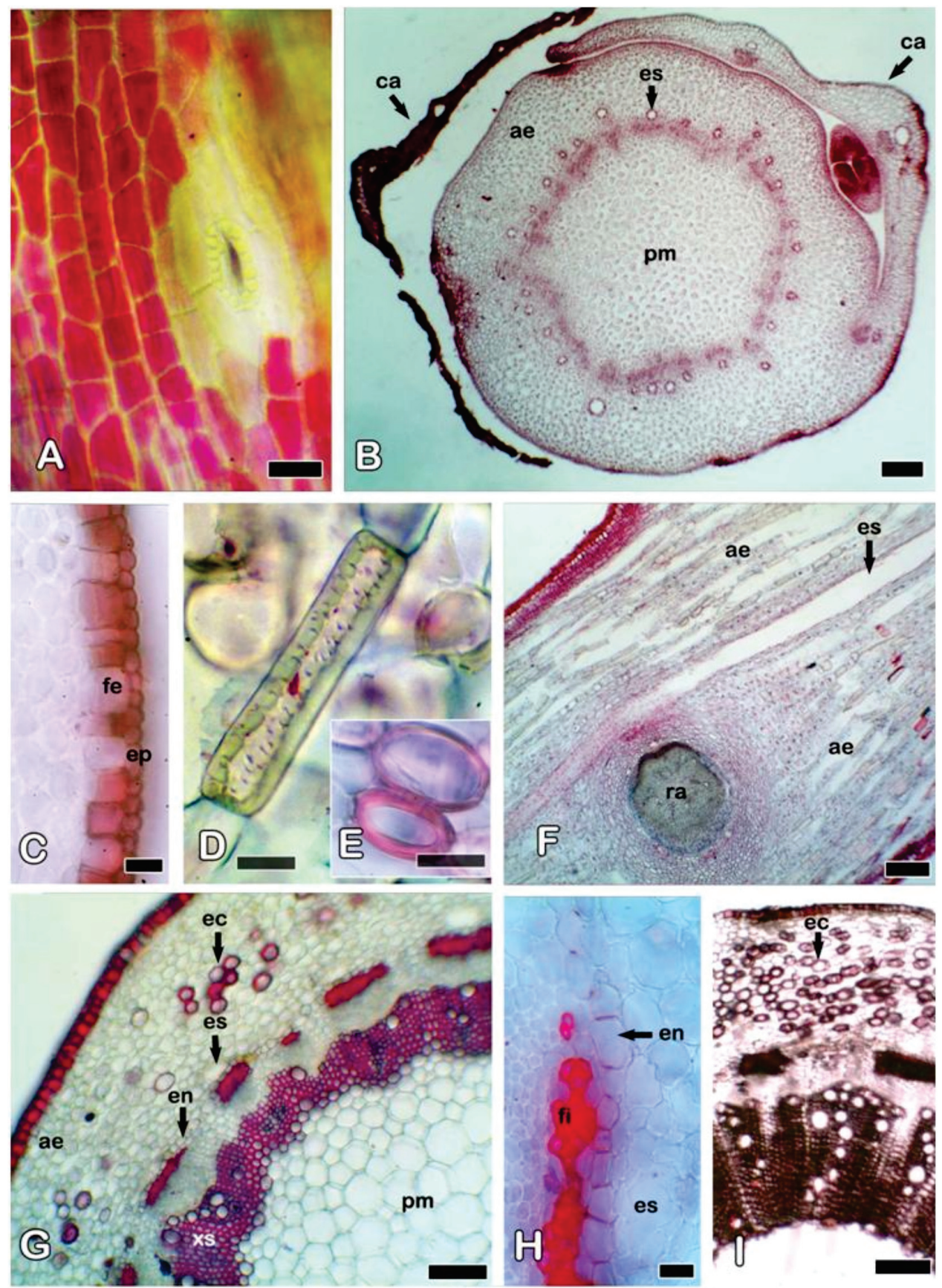

Fig. 6. Solidago chilensis var. chilensis. Rizoma, microscopio óptico. A) Vista superficial de la zona distal. B] Aspecto general en la zona distal, CT. C) Detalle de epidermis y felógeno en la zona distal, CT. D) Esclereidas de la corteza aerenquimática, CL. E) Esclereida de la corteza, CT. F) Espacio secretor de la zona distal, CL. G] Aspecto general en la zona media, CT. H) Detalle de la endodermis con bandas de Caspary en la zona media, CT. I) Aspecto general en la zona proximal, CT. Referencias: ae, aerénquima; ca, catafilo; CL, corte longitudinal; CT, corte transversal. en, endodermis; ep: epidermis; es, espacio secretor esquizógeno; ec, esclereida; fi, fibras; fe: felógeno; pm: parénquima medular; ra, raíz adventicia; xs, xilema secundario. Barras: A, C-E, H: $20 \mu \mathrm{m}$; B, F, I: $200 \mu \mathrm{m}$; G: $100 \mu \mathrm{m}$. 

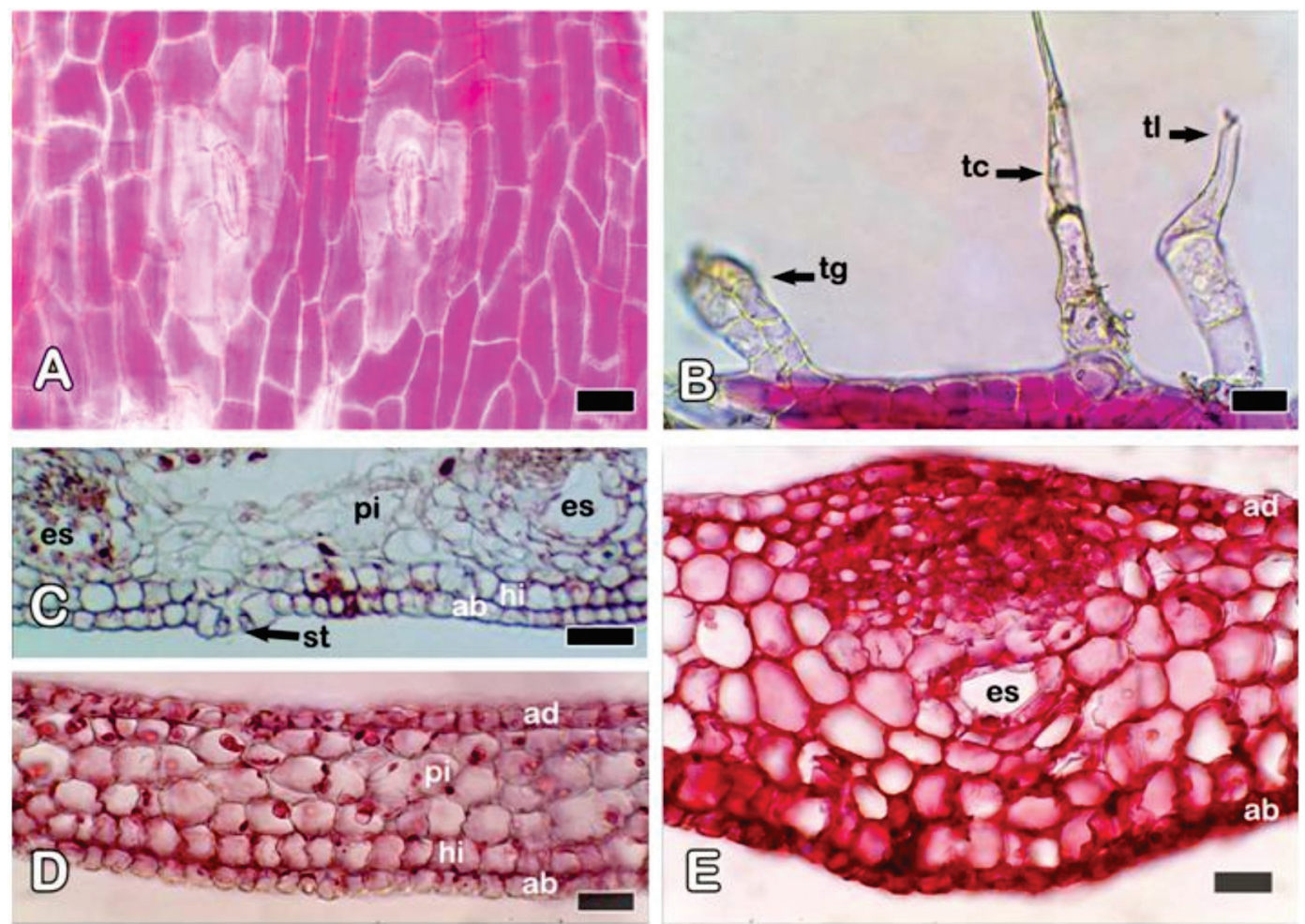

Fig. 7. Solidago chilensis var. chilensis. Catafilos de la zona distal del rizoma, microscopio óptico. A] Vista superficial. B] Tricomas glandulares y eglandulares en margen de catafilo, CT. C-D) Detalles de la estructura interna: epidermis y mesofilo, CT. E] Vena media, CT. Referencias: ab, epidermis abaxial; ad, epidermis adaxial; CT, corte transversal; es, espacio secretor esquizógeno; hi, hipodermis; pi, parénquima incoloro; st: estoma; tc, tricoma eglandular cónico; tg, tricoma glandular; tl, tricoma eglandular látigo o flageliforme. Barras: A, B, D, $\mathrm{E}: 20 \mu \mathrm{m}$; C: $50 \mu \mathrm{m}$.

\section{DISCUSIÓN Y CONCLUSIONES}

En Asteraceae es común la presencia de estructuras de secreción especializadas, ya sea tricomas glandulares, espacios secretores o ambos (Metcalfe y Chalk, 1979; Fahn, 1988). Los tricomas glandulares biseriados de Solidago chilensis var. chilensis sólo fueron citados por Hernández et al. (2013) en hojas y denominados biseriados vesiculosos, pero su distribución en la planta no fue evaluada. En nuestro estudio se ha podido comprobar la presencia de tricomas glandulares (tipo III) sólo en la zona distal de los vástagos. Por su ubicación, estos tricomas podrían estar relacionados con la defensa antiherbívoro y la protección de las estructuras jóvenes de las plantas (Uphof, 1962).
En cuanto a los espacios secretores esquizógenos, también denominados reservorios de lípidos (Lersten y Curtis, 1989), fueron encontrados en todos los órganos vegetativos de Solidago chilensis var. chilensis, tanto aéreos como subterráneos. La cantidad y localización de estas estructuras secretoras no coincide totalmente con trabajos previos para la especie. Hernández et al. (2013) encontraron de uno a tres espacios secretores por haz en el rizoma, mientras que en las hojas, Hernández et al. (2013, 2015) y Souza et al. (2017) citan un solo espacio secretor y siempre cercano al floema de cada haz vascular. Por otro lado, la posición de los espacios secretores en las hojas de las diferentes zonas del tallo, en conjunto con 

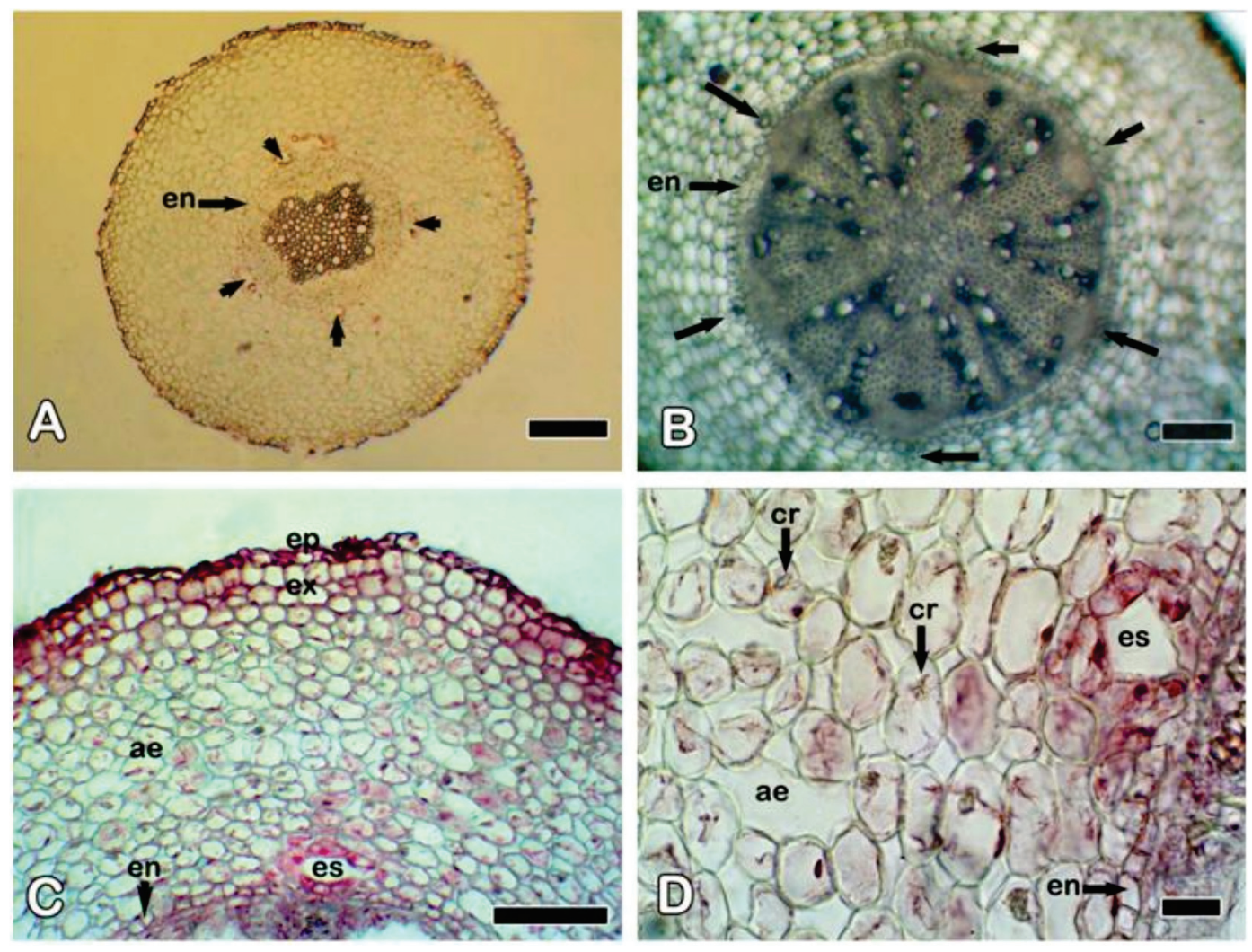

Fig. 8. Solidago chilensis var. chilensis. Estructura interna de la raíz adventicia, corte transversal, microscopio óptico. A) Aspecto general de raíz con crecimiento primario (flechas señalan espacios secretores esquizógenos]. B] Cilindro central y endodermis de raíz con crecimiento secundario (flechas señalan espacios secretores esquizógenos). C) Detalle de epidermis y corteza. D) Detalle de aerénquima cortical y espacio secretor. Referencias: ae, aerénquima; $\mathrm{cr}$ : cristales; en, endodermis; ep: epidermis; es, espacio secretor esquizógeno; ex, exodermis. Barras: A: $200 \mu \mathrm{m}$; B, D: $100 \mu \mathrm{m}$; C: $20 \mu \mathrm{m}$.

la variabilidad de tamaño del lumen según el orden de importancia de las venas, es similar a lo informado por Lersten y Curtis (1989) para Solidago canadensis L., especie de América del Norte.

Souza et al. (2017) encontraron aceites esenciales en las cavidades secretoras de Solidago chilensis Meyen. La amplia distribución de los espacios secretores en hojas, tallos, rizomas y raíces y su ubicación cercana al floema primario o secundario, harían suponer que estos fitoquímicos juegan un rol protector importante frente a insectos que se alimentan de los jugos floemáticos (Lersten y Curtis, 1989). Por otra parte, el tamaño conspicuo de los espacios en el tallo y hojas del nivel apical podría estar re- lacionado con la defensa de insectos desde los primeros estados de desarrollo de estos órganos (Lersten y Curtis, 1989).

El tipo de indumento y la longitud de los tricomas de los tallos adultos son caracteres taxonómicos empleados para diferenciar las especies de Solidago de América del Sur (López Laphitz y Semple, 2015). Estos autores describen los tallos de Solidago chilensis var. chilensis de Argentina como glabrescentes, con tricomas cortos, de menos de $0,5 \mathrm{~mm}$, coincidiendo con lo observado en este trabajo. Por otro lado, los tricomas tipo I (látigo o flageliformes) se encuadran dentro de los citados como bulbíferos flagelados por Gil et al. (2012) para la especie. 
Los espacios intercelulares del aerénquima están interconectados longitudinalmente permitiendo la rápida difusión de gases desde las hojas hasta los órganos subterráneos y son una adaptación de las plantas a condiciones de hipoxia o pobre aireación en ambientes acuáticos o en suelos anegados (Evert, 2008). La presencia de aerénquima en Solidago chilensis var. chilensis es un aspecto histológico destacable ya que es una especie de hábitat terrestre que vive en una amplia variedad de ambientes, tanto en suelos poco fértiles, como humíferos y húmedos cerca de fuentes de agua (Marzocca, 1997). Además, el desarrollo de aerénquima también en ejemplares creciendo bajo riego controlado implicaría que esta característica anatómica no es inducida por condiciones ambientales específicas sino que es un mecanismo preadaptativo de la especie (Barrientos, 2015).

Por otra parte, Solidago chilensis var. chilensis presenta aspectos anatómicos xeromórficos. Las hojas y tallos exhiben cutícula gruesa y estriada; numerosos estomas por unidad de superficie foliar y en ambas epidermis, pubescencia, células epidérmicas pequeñas con paredes rectas y mesofilo isolateral; presencia de ceras epicuticulares en tallos; antocianinas en epidermis de hojas, tallos, catafilos y rizomas jóvenes; antocianinas en el colénquima y abundantes fibras xilemáticas y floemáticas. Estas características adaptativas, coincidentes con lo expresado por Fahn (1982), sumado a las atractivas inflorescencias de la especie (Cuesta et al., 2006), harían adecuada a $S$. chilensis para las prácticas de xerojardinería (Gil et al., 2012).

La forma y distribución de cristales en las plantas está genéticamente controlada por las células, lo cual permite que sean usados en la clasificación e identificación de taxones (Meric, 2008). Los tipos de cristales predominantes en las partes vegetativas de Solidago chilensis var. chilensis fueron ráfides y estiloides de oxalato de calcio y su distribución en la planta fue heterogénea. Por el contrario, Souza et al. (2017) encontraron sólo ráfides en el parénquima de raíz, tallo y hoja de esta especie, mientras que Hernández et al. (2013) hallaron cristales de inulina, abundantes en la corteza y la médula del rizoma y, en menor cantidad, en la médula del tallo de $S$. chilensis var. chilensis. Sin embargo, la abundancia de los cristales en los tejidos puede variar según los niveles de calcio en el suelo (Franceschi y Nakata, 2005). Diversos representantes de la tribu Astereae (Conyza Less., Aster L., Bellis L. y Baccharis L.) (Meric, 2008, 2009; Bobek et al., 2016) también presentan cristales de oxalato de calcio, pero los tipos y distribución difieren de los observados en Solidago chilensis var. chilensis.

Los caracteres anatómicos foliares de $S$. chilensis var. chilensis son muy similares a los de otros representantes del género tales como $S$. canadensis, S. altissima L., S. gigantea Aiton y $S$. virgaurea L.: tres tipos de tricomas, cutícula gruesa con estriaciones, espacios secretores, hojas anfiestomáticas y mesofilo isolateral, excepto en $S$. virgaurea, donde es dorsiventral (Lersten y Curtis, 1989; Szymura y Wolski, 2011).

El análisis anatómico del vástago y del rizoma de Solidago chilensis var. chilensis en estado vegetativo permite incorporar nueva información que amplía y profundiza los trabajos anatómicos previos sobre la especie. Además, el análisis de distintas zonas del vástago y rizoma demuestra variaciones en distintos tejidos y estructuras, más allá de las predecibles. Por ejemplo, el tipo y densidad de tricomas, densidad de estomas, tamaño de espacios secretores, desarrollo del aerénquima y distribución de cristales. Esta significación no había sido considerada en estudios convencionales previos donde sólo se informa el análisis de un único sector del vástago. Teniendo en cuenta que todas las partes de la planta son de interés etnobotánico, la caracterización de diferentes zonas o niveles del vástago y rizoma es relevante al momento de identificar especies de valor medicinal de otras que no lo son, especialmente de las que se desconocen sus efectos en humanos, y para poder evitar adulteraciones o sustituciones en las mezclas herbarias comercializadas. 
Las variaciones observadas en los órganos vegetativos de Solidago chilensis var. chilensis $\mathrm{y}$, en especial, la distribución heterogénea y el diferente desarrollo de las estructuras secretoras (tricomas glandulares y espacios secretores) en la diferentes zonas del vástago y rizoma, avalarían futuros estudios fitoquímicos referentes a los compuestos presentes en cada nivel del órgano. Esto, en conjunto con el estado fenológico de las plantas, serán importantes caracteres para decidir el momento óptimo de cosecha y los órganos o partes de órganos a recolectar en función de los compuestos que se deseen obtener.

\section{AGRADECIMIENTOS}

Este trabajo fue financiado con una beca Estímulo a las Vocaciones Científicas del Consejo Interuniversitario Nacional de la segunda autora y un subsidio de investigación del Departamento de Ciencias Básicas de la Universidad Nacional de Luján. Agradecemos al Servicio de Microscopía Electrónica de Barrido del Museo Argentino de Ciencias Naturales Bernardino Rivadavia por la preparación de muestras y toma de fotografías.

\section{BIBLIOGRAFÍA}

Ahumada, H., Alonso, S., Amuchástegui, A., Braun, K., Cáceres, E., Cantero, J., Villamil, C. B. (2016). Descripción de las especies. En: O. Fernández, E. S. Leguizamón y H. A. Acciaresi [Eds.], Malezas invasoras de la Argentina II: Descripción y reconocimiento (pp. 83912). Bahía Blanca, Argentina: Universidad Nacional del Sur.

Alonso, J. y Desmarchelier, C. (2015). Plantas medicinales autóctonas de la Argentina: Bases científicas para su aplicación en atención primaria de la salud. Buenos Aires, Argentina: Corpus Libros Médicos y Científicos.

Arambarri, A. M. y Hernández, M. P. (2014). Variación estacional de saponinas en Solidago chilensis var. chilensis (Asteraceae). Boletín de la Sociedad Argentina de Botánica 49 (4): 483-489.

Barboza, G. E., Cantero, J. J., Núñez, C. O., Pacciaroni, A. y Ariza Espinar, L. (2009). Medicinal plants: a review and a phytochemical and ethnopharmacological screening of a native Argentine Flora. Kurtziana 34 (1-2): 7-365.

Barboza, G. E., Bonzani, N., Filippa, E. M., Luján, M. C., Moreno, R., Bugatti, M., Ariza Espinar, L. (2001). Atlas histomorfológico de plantas de interés medicinal de uso corriente en Argentina. Córdoba, Argentina: Museo Botánico de Córdoba, Serie especial I.

Barrientos, G. (2015). Optimización del rendimiento del cultivo de Solidago chilensis Meyen var. chilensis (Asteraceae) en el partido de Luján, provincia de Buenos Aires. (Informe final de Beca EVC-CIN), Universidad Nacional de Luján, Argentina.

Bobek, V. B., Heiden, G., Oliveira, C. F., Almeida, V. P., De Paula, Farago, P., Budel, J. M. (2016). Comparative analytical micrographs of "vassouras» (Baccharis, Asteraceae). Revista Brasileira de Farmacognosia 26 (1): 665-672. doi:10.1016/j.bjp.2016.05.001.

Bucciarelli, A., Minetti, A., Milczakowskyg, C. y Skliar, M. (2010). Evaluation of gastroprotective activity and acute toxicity of Solidago chilensis Meyen (Asteraceae). Pharmaceutical Biology 48 (9): 1025 1030. doi:10.3109/1388020090345 3131.

Colares, M. N., Hernández, M. P., Novoa, M. C., Perrotta, V. G., Auguet, S. y Arambarri, A. M. (2014). Anatomía comparada de raíces medicinales de hierbas rioplatenses (Buenos Aires, Argentina). Dominguezia 30 (1): 5-17.

Cuesta, G., Vespa, J., Sánchez, V., Videla, E., Fioretti, S. y Cialli, A. [2006). Estudios preliminares sobre la adaptación de "penacho amarillo» (Solidago chilensis) con fines ornamentales. III Congreso Argentino de Floricultura, VIII Jornadas Nacionales de Floricultura. La Plata. Buenos Aires.

D’Ambrogio de Argüeso, A. (1986). Manual de técnicas en histología vegetal. Buenos Aires, Argentina: Hemisferio Sur.

Evert, R. F. (2008). Esau Anatomía Vegetal: meristemas, células y tejidos de las plantas, su estructura, función y desarrollo. Barcelona, España: Omega.

Fahn, A. (1982). Anatomía vegetal. Madrid, España: Ediciones Pirámide.

Fahn, A. (1988). Secretory tissues in vascular plants. New Phytologist 108: 229257.

Franceschi, V. R. y Nakata, P. A. (2005). Calcium oxalate in plants: formation and function. Annual Review of Plant Biology 56: 41-71. doi: 10.1146/annurev.arplant.56.032604.144106. 
Freire, S. E., Arambarri, A. M., Bayón, N. D., Sancho, G., Urtubey, E., Monti, C., Colares, M. N. [2005). Epidermal characteristics of toxic plants for cattle from the Salado River basin (Buenos Aires, Argentina). Boletín de la Sociedad Argentina de Botánica 40 (3-4): 241-281.

Gil, S. P., Seisdedos, L., Reyna, M. E. y Cerana, M. M. (2012). Epidermis foliar de tres especies de asteráceas nativas de Argentina con potencial ornamental. Phyton (Buenos Aires) 81 (2): 205-210.

Güntner, C., Barra, C., Cesio, M. V., Dellacassa, E., Ferrando, L., Ferreira, F., Moyna, P. (1999). Antioxidant properties of Solidago chilensis L. flavonoids. Acta Horticulturae 501: 159-163. doi: 10.17660/ActaHortic. 1999.501.23.

Hernández, M. P., Martínez Alonso, S. M, Morandi, L. A. y Arambarri, A. M. (2013). Anatomical and chemical analysis in Solidago chilensis var. chilensis (Asteraceae). Latin American Journal of Pharmacy 32 (8): 1236-1240.

Hernández, M. P., Novoa, M. C, Colares, M. N., Perrotta, V. G., Nughes, L. M. y Arambarri, A. M. (2015). Anatomía foliar de hierbas terrestres medicinales que crecen en la región rioplatense (Buenos Aires, Argentina). Bonplandia 24 (2): 97-123.

Lahitte, H. B., Hurrell, J. A., Belgrano, M. J., Jankowski, L. S., Haloua, M. P. y Mehltreter, K. (1998). Plantas medicinales rioplatenses. Buenos Aires, Argentina: L.O.L.A.

Lersten, N. R. y Curtis, J. D. (1989). Foliar oil reservoir anatomy and distribution in Solidago canadensis (Asteraceae, tribe Astereae). Nordic Journal of Botany 9: 281-287. doi: 10.1111/j.17561051.1989.tb01003.x.

López Laphitz, R. M. y Semple, J. C. (2015). A multivariate morphometric analysis of the Solidago chilensis group in South America and related taxa in North America (Asteraceae, Astereae). Annals of the Missouri Botanical Garden 100 (4): 423-441. doi: 10.3417/2014023.

Marzocca, A. (1997). Vademecum de malezas medicinales de la Argentina: Indígenas y exóticas. Buenos Aires, Argentina: Orientación Gráfica Editora.

Mercandeli, A. A., Bessa, G. P., Ronchi, S. N., Segato, T. P. S y da Silva, A. G. (2012). Evidence for the safe use of the extract from the Brazilian arnica, Solidago chilensis Meyen, in primary health care. Chinese Medicine 3: 4-8 doi: 10.4236/cm.2012.31002.
Meric, C. (2008). Calcium oxalate crystals in Conyza canadensis (L.) Cronq. and Conyza bonariensis (L.) Cronquist (Asteraceae: Astereae). Acta Biologica Szegediensis 52 (2): 295-299.

Meric, C. (2009). Calcium oxalate crystals in Aster squamatus and Bellis perennis (Asteraceae: Astereae). Phytologia Balcanica 15 (2): 255-259.

Metcalfe, C. R. y Chalk, L. (1979). Anatomy of the Dicotyledons. Systematic anatomy of the leaf and stem. Vol. I. Oxford, Inglaterra: Clarendon Press.

Rodríguez Morcelle, M. I., Lus, B. A., Bosco, S., Wilson, E., Costaguta, M. y Apóstolo, N. M. (2015). Análisis de compuestos fenólicos de Solidago chilensis var. chilensis. Boletín de la Sociedad Argentina de Botánica 50 (supl.): 192-193.

Sancho, G., Viera Barreto, J. y Vitali, M. (2014). Tribu Astereae. En: F. Zuloaga, M. Belgrano y A. Anton (Eds.), Flora vascular de la República Argentina 7 (1): Dicotyledoneae-Asteraceae (Anthemideae a Gnaphalieae) (pp. 38-246). San Isidro, Argentina: Instituto de Botánica Darwinion.

Silva, A. G., De Sousa, C. P., Koehler ,J., Fontana, J., Christo, A. G. y GuedesBruni, R. R. (2010). Evaluation of an extract of Brazilian arnica (Solidago chilensis Meyen, Asteraceae) in treating lumbago. Phytotherapy Research 24: 283-287. doi: 10.1002/ptr.2934.

Souza, D. M. F, Sá, R. D., Araújo, E. L. y Randau, K. P. (2017). Anatomical, phytochemical and histochemical study of Solidago chilensis Meyen. Anais da Academia Brasileira de Ciências Río de Janeiro. doi: 10.1590/00013765201720160280.

Szymura, M. y Wolski, C. (2011). Leaf epidermis traits as tools to identify Solidago L. taxa in Poland. Acta Biologica Cracoviensia Series Botanica 53 (1): 38-46. doi: 10.2478/v10182-011-0006-3.

Tamura, E. K., Spada Jimenez, R., Waismam, K., Gobbo-Neto, L., Peporine Lopes N., Malpezzi Marinho, E. A. L,. Farsky, S. H. P. (2009). Inhibitory effects of Solidago chilensis Meyen hydroalcoholic extract on acute inflammation. Journal of Ethnopharmacology 122 (3): 478-485. doi: 10.1016/j.jep.2009.01.029.

Uphof, J. C. T. (1962). Plant hairs. Berlín, Alemania: Gebruder Borntraeger.

Vila, R., Mundina, M., Tomi, F., Furlán, R., Zaccino, S., Casanova, J. y Cañigueral, S. (2002). Chemical composition and antifungal activity of the essential oil 
of Solidago chilensis. Planta Medica 68: 164-167. doi: 10.1055/s-200220253.

Zarlavsky, G. E. (2014). Histología vegetal: técnicas simples y complejas. Buenos Aires, Argentina: Sociedad Argentina de Botánica. 